\title{
A MULTICENTRIC COMPARATIVE STUDY IDENTIFYING ‘RESEARCH OBSTACLES’ AMONG POSTGRADUATE RESIDENTS OF DIFFERENT `MEDICAL \& DENTAL INSTITUTES OF BALOCHISTAN AND PUNJAB'
}

\author{
Nabiha Farasat Khan, Muhammad Saeed, Imran Saeed*, Arshad Kamal Butt** \\ Bolan University of Medical \& Health Sciences, Quetta Pakistan, *The Children's Hospital, Lahore Pakistan, **Shaikh Zayed Hospital, Lahore Pakistan
}

\section{ABSTRACT}

Objective: To compare the research obstacles including lack of proper training, previous exposure, time management, motivation, faculty research knowledge, skill, social constrains and lack of interest among post-graduate residents of Balochistan with those of Children's Hospital, Lahore.

Study Design: Comparative cross-sectional study.

Place and Duration of Study: Dental College, Bolan University of Medical and Health Sciences, Quetta, Quetta Institute of Medical Sciences \& Institute of Public Health of Balochistan, from Mar to May 2018, and Children's Hospital Lahore, Lahore, from Jul to Aug 2017.

Methodology: A total of 72 postgraduates from three different institutes of Balochistan and 90 from Children's Hospital, Lahore were recruited in this study. The questionnaire was distributed to the participants of both institutions; data was collected \& entered into SPSS version 22.

Results: Female predominance $(64.4 \%)$ was observed in post-graduates of Children's Hospital, Lahore in comparison to institutions from Balochistan while there were $61 \%$ males. Majority $(90 \%)$ post-graduate residents of Balochistan recognized time management, deficient laboratory and other facilities followed by lack of mentoring by faculty 59 (83\%) and lack of motivation $60(84 \%)$ as the most important factors that hinder their scientific activities. Additionally, $91(86.6 \%)$ postgraduates of Children's Hospital, Lahore suggested lack of proper research training and 87 (83.3\%) suggested lack of previous exposure as the main hindering factors in their research work.

Conclusion: Post-graduate residents of diverse economic, educational and cultural backgrounds present different perceptions about research hurdles. However, those from both provinces identified that lack of mentoring, deficient laboratory and other facilities, lack of time and lack of motivation were the major factors which were influenced their research work.

Keywords: Comparison, Dentistry, Medicine, Postgraduate trainees, Research hurdles.

How to Cite This Article: Khan NF, Saeed M, Saeed I, Butt AK. A Multicentric Comparative Study Identifying 'Research Obstacles' Among Postgraduate Residents of Different 'Medical E Dental Institutes of Balochistan and Punjab'. Pak Armed Forces Med J 2021; 71(6): 1941-1946. DOI: https://doi.org/10.51253/pafmj.v6i6.3484

\footnotetext{
This is an Open Access article distributed under the terms of the Creative Commons Attribution License (https://creativecommons.org/licenses/by-nc/4.0/), which permits
} unrestricted use, distribution, and reproduction in any medium, provided the original work is properly cited.

\section{INTRODUCTION}

Research in clinical practice by health professionals that not only provides grounded diagnosis but also enhances their critical appraisal abilities, assists in decision making and keeps students and professionals connected with current developments in their field thus bridging the gap between science and practice. ${ }^{1}$ In developed countries, research is integrated into their training course; institutes ensure availability of research centers with well-equipped labs and advanced devices, and provide financial support to students' that increases and strengthens their participation in research. ${ }^{2}$ Resource constrained developing countries may not be able to emulate their western developed counter parts but efforts to promote quality research seen in developing countries exemplified by Malaysia are an

Correspondence: Dr Nabiha Farasat Khan, Oral Pathology, Bolan University of Medical \& Health Sciences, Quetta Pakistan

Received: 13 Nov 2019; revision received: 27 May 2020; accepted: 08 Jun 2020 important step in the right direction. ${ }^{3}$ Pakistan Medical Research Council (PMRC) was established in 1957 to promote research in Pakistan which led to an increase in published research from various institutions. ${ }^{4}$ In a country of over twenty two million million with huge unresolved health issues, considerable efforts are needed to overcome hurdles that are hindering research activities of medical professional and students. ${ }^{1,4,5} \mathrm{Al}-$ though many researchers in Pakistan have assessed research hurdles among graduate/postgraduate medical and dental students, ${ }^{1,5-7}$ However none of these reports have compared the obstacles perceived by researchers in different fields with each other or with the results of other provinces.

This study was, therefore, conducted to assess the perceptions of post-graduate residents of Balochistan which is relatively less privileged province of Pakistan about research obstacles and to compare the data with the experiences of postgraduate residents of Children's Hospital, Lahore, Punjab. 


\section{METHODOLOGY}

A comparative cross-sectional study was carried out at 3 different medical and dental institutes of affiliated with Bolan University of Medical and Health Sciences (BUMHS) Quetta, Bolan Medical Complex Hospital (BMCH), Quetta Institute of Medical \& Health Sciences (QIMS) and Institute of Public Health (IPH]) and Children's Hospital, Lahore, from May to July 2017 from Children's Hospital, Lahore and from 3 institutes of Balochistan (BMCH, QIMS \& IPH) during March-May 2018. After taking Ethical approval from both institutes (MME/1/08 Children's hospital, Lahore \& No. Admn-1/BMC/2018/3620/22 from Bolan University of Medical and Health Sciences, Quetta), confirmation of confidentiality and taking consent from postgraduate residents from Balochistan \& Punjab, questionnaire was distributed; non-probability consecutive sampling technique was used.

Inclusion Criteria: All the participants working as PG residents in $\mathrm{BMCH}$, QIMS and IPH from Balochistan and Children's Hospital, Lahore were included in the study.

Exclusion Criteria: House officers \& Senior Registrars from Balochistan and Senior Registrars from Children's Hospital, Lahore were excluded.

Researchers from both provinces utilized validated questionnaire (formulated by Amin \& Sheikh respectively). ${ }^{1,8}$ Authors utilized non-probability convenient sampling technique with all available and consenting participants included.

Previously a researcher from Children's Hospital, Lahore utilized 18 items to check the perception of postgraduate residents whereas we applied only 10 items that work as obstacles in their research activities. The obstacles included in this comparison were; lack of proper mentoring, uncooperative faculty, deficient laboratory and other facilities, lack of time, low motivation/rewards, deficient faculty research knowledge and skills, lack of funding, inaccessibility of data, deficient knowledge and skills of research in trainees and low interest level.

Responses of participants were recorded on a 5-point Likert scale (1-Strongly disagree, 2-Disagree, 3Neutral, 4-Agree and 5-Strongly Agree). The variables on likert scale were recoded for further analysis by combining categories agree and strongly agree in to a single group agree recoded 3, categories strongly disagree and disagree into a single category disagree coded as 1 while neutral was retained and coded as 2 .
Data was analyzed statistical package for social science (SPSS) version 22. Frequencies and percentages were calculated for qualitative data and analyzed with Chi-square test. Mean scores and standard deviations were calculated for each of the ten variables mentioned above with higher scores indicating greater degree of agreement. Comparison of age was done with t-test. The $p$-value was considered statistically significant at $\leq 0.05$.

\section{RESULTS}

Ninety of 105 eligible postgraduate residents from Children's Hospital, Lahore and 72 out of 80 from 3 different medical and dental institutes of Balochistan; 38 from $\mathrm{BMCH}, 15$ from QIMS \& 19 from IPH, the remaining 8 subjects were absent at the time of data collection returned the questionnaire giving $72(90 \%)$ response rate from Balochistan versus 90 (86\%) from Children's Hospital, Lahore. Comparatively, male postgraduate residents were predominant 64 (61\%) from Balochistan and females from Children's Hospital, Lahore. Participants from Balochistan were, on the average 5 years younger than those from Punjab while no difference in marital status was found between the two provinces. Detailed demographic analysis of postgraduate residents of both provinces as presented in Table-I.

Table-I: Demographic characteristics of postgraduate residents.

\begin{tabular}{|c|c|c|c|}
\hline $\begin{array}{l}\text { Charac- } \\
\text { teristics }\end{array}$ & $\begin{array}{l}\text { Postgraduate } \\
\text { Residents } \\
\text { from } \\
\text { Balochistan } \\
(\mathrm{n}=80)\end{array}$ & $\begin{array}{l}\text { Postgraduate } \\
\text { residents from } \\
\text { Children's } \\
\text { Hospital, } \\
\text { Lahore (n=105) }\end{array}$ & $\begin{array}{c}p- \\
\text { value }\end{array}$ \\
\hline Response rate & $72(90)$ & $90(86)$ & \\
\hline \multicolumn{4}{|l|}{ Gender } \\
\hline Males & $44(61.1 \%)$ & $32(35.5 \%)$ & \multirow{2}{*}{$0.002^{*}$} \\
\hline Females & $28(38.8 \%)$ & $58(64.4 \%)$ & \\
\hline \multicolumn{4}{|l|}{ Age (Year) } \\
\hline Mean \pm SD & $23.3 \pm 4.6$ & $28.22 \pm 2.09$ & $<0.001^{* \star}$ \\
\hline \multicolumn{4}{|l|}{ Marital Status } \\
\hline Married & $37(51.4)$ & $33(36.7)$ & \multirow{2}{*}{$* 0.079^{*}$} \\
\hline Unmarried & $35(48.6)$ & $57(63.3)$ & \\
\hline
\end{tabular}

Table-II presents distribution of scores on 10 variables in our study addressing Attitudes and Perceptions about Barriers in scientific research among the dental and medical post-graduate students from Balochistan. Table-III presents comparison of opinions expressed by Post-graduates from both the provinces on 10 variables.

Factors that hinder research work in the provinces of Punjab and Balochistan are presented in Table-IV. 
Participants from Children's Hospital, Lahore identified lack of proper training of research, lack of previous research exposure and lack of time as main hurdles while participants from Balochistan favored lack of time and lab facilities, absence of motivation and deficient faculty research knowledge and skills as the main factors.

\begin{tabular}{|c|c|}
\hline Barriers to Research Scores & Mean \pm SD \\
\hline Lack of proper mentoring from faculty & $4.12 \pm 0.99$ \\
\hline Uncooperative faculty & $3.83 \pm 0.91$ \\
\hline Lack of time & $4.23 \pm 0.91$ \\
\hline Lack of proper lab and other facilities & $4.30 \pm 0.76$ \\
\hline Deficient faculty research knowledge and skill & $3.87 \pm 1.04$ \\
\hline Inaccessibility of electronic and medical data & $4.00 \pm 0.97$ \\
\hline Lack of funding & $3.86 \pm 1.17$ \\
\hline Lack of motivation and or rewarding & $4.23 \pm 0.77$ \\
\hline $\begin{array}{l}\text { Lack of appropriate knowledge and skill of } \\
\text { research }\end{array}$ & $3.79 \pm 1.00$ \\
\hline Lack of interest & $3.38 \pm 1.32$ \\
\hline
\end{tabular}

Table-III: Comparison of opinions of Postgraduates from Children's Hospital, Lahore and Postgraduates from Quetta

\begin{tabular}{l|c|c}
\hline Parameters & $\begin{array}{c}\text { Children's } \\
\text { Hospital, } \\
\text { Lahore n (\%) }\end{array}$ & $\begin{array}{c}\text { Quetta } \\
\text { Institutions } \\
\text { n (\%) }\end{array}$ \\
\hline $\begin{array}{l}\text { Lack of proper mentoring } \\
\text { from faculty* }\end{array}$ & $56(62.2)$ & $60(83.3)$ \\
\hline Uncooperative faculty & $49(54.4)$ & $50(69.4)$ \\
\hline Lack of time* & $74(82.2)$ & $65(90.3)$ \\
\hline $\begin{array}{l}\text { Lack of proper lab and other } \\
\text { facilities* }\end{array}$ & $52(57.8)$ & $65(90.3)$ \\
\hline $\begin{array}{l}\text { Deficient faculty research } \\
\text { knowledge and skill }\end{array}$ & $67(74.4)$ & $49(68.1)$ \\
\hline $\begin{array}{l}\text { Inaccessibility of electronic } \\
\text { and medical data }\end{array}$ & $56(54.5)$ & $55(76.4)$ \\
\hline Lack of funding & $61(67.8)$ & $53(73.6)$ \\
\hline $\begin{array}{l}\text { Lack of motivation and or } \\
\text { rewarding* }\end{array}$ & $69(76.7)$ & $61(84.7)$ \\
\hline $\begin{array}{l}\text { Lack of appropriate know- } \\
\text { ledge and skill of research }\end{array}$ & $67(74.4)$ & $53(73.6)$ \\
\hline Lack of interest & $46(51.1)$ & $37(51.4)$ \\
\hline${ }^{* p-v a l u e<0.05 ~ b a s e d ~ o n ~ C h i-s q u a r e ~ t e s t ~}$
\end{tabular}

\section{DISCUSSION}

This cross-sectional study of postgraduate trainees from two different provinces of Pakistan was undertaken to identify and compare the perceptions of trainees about possible hurdles to research in their institutions. Comparison of demographic view (response rate, age, gender and marital status of postgraduate residents) between current study and the study conducted by Imran from Children's Hospital, Lahore has provided important data to inform decisions on improving research culture. Good response rates of $86 \%$ by Imran S from Children's Hospital, Lahore and $90 \%$ from the three surveyed institutions of Quetta were reported. Different researchers from diverse communities assessed research hurdles among under and postgraduate medical students and reported good response rates in their studies. ${ }^{9,10} \mathrm{Amin}^{2}$ in his study from King Faisal University, Kuwait University \& Arab Gulf University reported response rates $91 \%, 64.8 \%$ \& $88 \%$ respectively. ${ }^{8}$ Soe from Malaysia \& Abushouk from Egypt noted $81.94 \%$ and $86 \%$ response rates respectively. 3,9 Sheikh SFA1 from King Edward Medical University, Lahore conducted research on research barriers and reported $100 \%$ response rate $(n=122) .{ }^{1}$ However, not all researchers achieved these response rates. Participation of Kharraz from Saudi Arabia was only $63.1 \% .10$ Although these studies were conducted in developing countries where educational level is not very high but still these studies reported good response rates. Participants from the present study has demonstrated postgraduate residents were aware of research obstacles and were willing to overcome these hurdles during their research work by communicating their perceptions to stake holders of medical colleges/universities and HEC \& PM\&DC.

Previous studies conducted on this topic in Egypt, Saudi-Arab \& Pakistan recognized predominant female medical students. ${ }^{1,8,9}$ Same was true in Imran's study where $64.4 \%$ (58/90) participants were females. ${ }^{5}$ In our study males were dominant $(61 \%, n=44 / 72)$.

Table-IV: Factors contributing lack of research in Postgraduate residents of 2 provinces.

Top 3 factors hindering research work of Postgraduate residents of different institutes of Lahore and Balochistan

\begin{tabular}{l|c|c|c}
\hline Institutes & $\begin{array}{c}\text { Factor with highest percentage } \\
\text { hindering postgraduate } \\
\text { residents research work }\end{array}$ & $\begin{array}{c}2^{\text {nd }} \text { Factor that hinders } \\
\text { postgraduate residents } \\
\text { research work }\end{array}$ & $\begin{array}{c}3^{\text {rd }} \text { commonest factors } \\
\text { hindering research work of } \\
\text { postgraduate residents }\end{array}$ \\
\hline $\begin{array}{l}\text { Children's Hospital, } \\
\text { Lahore }\end{array}$ & $\begin{array}{c}\text { Lack of proper training of } \\
\text { research, 78 (86.6) }\end{array}$ & $\begin{array}{c}\text { Lack of previous } \\
\text { exposure, 75 (83.3) }\end{array}$ & Lack of time 74 (82.2) \\
\hline $\begin{array}{l}\text { Combined results of Bolan } \\
\text { University of Medical \& Health } \\
\begin{array}{l}\text { Sciences, Quetta Institute of Medical } \\
\text { Sciences \& Institute of Public Health }\end{array}\end{array}$ & $\begin{array}{c}\text { Lack of time \& lack of lab \& } \\
\text { other facilities each } \\
\text { respectively), 65 (90) }\end{array}$ & $\begin{array}{c}\text { Lack of motivation and } \\
\text { or rewarding 61 (84) }\end{array}$ & $\begin{array}{c}\text { Deficient mentoring by } \\
\text { faculty, } 49(83 \%)\end{array}$ \\
\hline
\end{tabular}


Educational background, lack of resources \& different conditions are the basis for these differences.11 An important factor of this dissimilarity is male dominant society and conservative/tribal culture in Balochistan where females are generally disadvantaged in all walks of life. ${ }^{12}$

Analysis of age in our sample indicated that participants from Lahore $(28.22 \pm 2.09)$ were on the average 5 years older than those from Quetta $(23.3 \pm 4.6)$ while participants of studies by Amin (21.4 \pm 1.4$)$, Dodipoor $(21.61 \pm 2.61)$ and Soe $(22.29 \pm 1.05)$ were younger. $2,3,8$ One possible reason for younger age group in the studies alluded to above is that participants of current study and Imran from Children's Hospital, Lahore, ${ }^{5}$ were postgraduate residents whereas participants of other researchers were undergraduate medical students. ${ }^{1,8,9}$ In our country, another possible reason that affects students research work could be that the present curricula of MBBS and BDS do not mention research work as mandatory for medical \& dental students who are therefore neither attracted to or obliged to focus attention towards this essential element and generally become untrained clinicians for future research work. 13,14

We analyzed reported studies conducted on research obstacles in under/postgraduate students that expressed the effect of marital status in the research work of postgraduate trainees.5,15,16 A good correlation exists between a person's marital status and his/her wellbeing as reported Odegaard in 1946 and Coombs in 1991 with greater satisfaction and longer lives of happily married couples due to their good emotional and physical health. ${ }^{17,18}$ Small sample size of the present study does not allow a robust conclusion whether marital status affects their educational life. More than half $(51.4 \%)$ postgraduate residents of current study from Balochistan were married versus $63.3 \%(n=57 / 90)$ of the study participants from Children's Hospital, Lahore. were unmarried. One-third (33/90) of married postgraduate residents identified increased family commitments hindering their research activities. This is probably because the supportive social and emotional encouragement from their cooperative family and partners reduces burdens and enhances their academic performance. ${ }^{19,20}$ Most of the married students, in current study, presented better academic performance. Analysis of marital status of our study participants identified lack of interest ( $p$-value-0.034) and lack of appropriate knowledge and skill of research $(p-0.043)$ as the only two variables where statistically significant differences were noted. This difference was not reflected in opinions of participants from Children Hospital, Lahore. It is likely that due to family responsibilities married students have better time management skills which encourage them to be focused and serious towards their studies. ${ }^{16}$ Another possible factor encouraging research of married participants could be the incentive of employment/promotion with their associated financial emoluments contributing to better monetary management of family expenses. ${ }^{16}$ Other items did not exhibit any correlation between marital status and research hurdles.

Although we emphasize on scientific research promotion but due to presence of barriers under/postgraduate students are unable to connect theory with practice. ${ }^{1}$ In current study, the most common obstacle stated by the postgraduate residents from Balochistan was item no. "Time management," that works as a crucial hurdle in the continuing of research work. Ninety percent postgraduate residents $(n=17 / 19)$ of Institute of Public Health, Quetta, face this problem during their post-graduation. Since work over-load and exam tension makes time management very difficult for under/post graduate medical students, so they identified it as a major obstacle towards research activities. ${ }^{5}$ Eighty-two percent postgraduate residents from Children's Hospital, Lahore recognized this item "Lack of time to conduct research" as a third major obstacle hindering their research work. ${ }^{5}$ We did not address the contribution of an inflated curriculum as a hurdle in our study where as $77.8 \%$ postgraduate residents from Imran Saeed study the recognized item "Over loaded curriculum" as a factor that might affect the work of postgraduate trainees during their scientific research activities. Practically, we can address this problem by organizing elective research programmes. ${ }^{21,22}$

An equally important obstacle identified by participants from Balochistan sample hindering scientific activities of under/post graduate students was Item number 4 "lack of proper lab and other facilities." Ninety percent postgraduate residents in the present study reported this factor as a major hurdle in research work. On the other hand, $57.8 \%$ post-graduate residents of Imran from Children's Hospital, Lahore recognized this as a significant item. ${ }^{5}$ Participants of Dadipoor from Iran confirmed lack of facilities obstructing their research work, and reported it to be the $2^{\text {nd }}$ most prevalent barrier in their research work. ${ }^{2}$ Soe also identified $63.3 \%$ study population documented lack of facilities as a hurdle in their work. ${ }^{3}$ The reason behind 
this deficiency could be the lack of funding from institution, which was not a major deterrent identified in developed countries. 2,3 This issue is generated due to the lack of educational and research-based facilities, and can be solved by sensitizing political leadership and government agencies to the extreme importance of research as a long-term investment towards national progress. Empowering Higher Education Commission with greater financial autonomy is a possible solution. ${ }^{4}$ Stakeholders should pay special attention to research budgets, especially of students' research. ${ }^{2}$

Intrinsic motivation reflects the human tendency to acquire and absorb from genuine interest, while extrinsic motivation results from either external control or true self-regulation. ${ }^{23}$ Students presenting balanced motivation (both internal/external motivation) demonstrate good academic performance. ${ }^{24}$ Researchers recognizes faculty/supervisor support and encouragement have a positive effect on motivation, while lack of faculty support presents negative effect. ${ }^{25}$ In current study, $3^{\text {rd }}$ most important obstacle in research work of postgraduate residents from Balochistan was Item No. 8 "Lack of Motivation/rewards," 84\% postgraduate residents admitted that they have been frustrated due to lack of reward or motivation. We found only minor differences between our results and those from Children's Hospital Lahore where $76.7 \%$ of the participants reported "lack of motivation" as a confounding factor in their research activity. ${ }^{5}$ However, other studies did not find this factor obstructing research activities of their study participants. ${ }^{3,8}$ A feasible approach in this context is to train faculty through capacity building programs on regular basis.

Eighty-three percent of respondents from Balochistan agreed that lack-of, mentoring from faculty hindered their research activities versus $62 \%$ from Children Hospital, Lahore. This difference of $20 \%$ was probably indicative of lesser sensitization of faculty in Quetta compared to Lahore since the later institution had implemented workshops on mentoring while in Quetta this approach was only beginning to be implemented.

Seventy-four percent respondents from Children's Hospital, Lahore identified Item No. 9 "lack of postgraduate resident's research knowledge and skills" as a significant obstacle 5 with an almost equal number $(73 \%$,) postgraduate residents of current study also declared it as an important element in decreasing research work capacity. Other studies did not present significant results on this item as Amin et al from Cairo found $39.2 \%$ medical students demonstrate lack of interest. ${ }^{8}$ Dodipoor, also reported this item as main personal barrier. ${ }^{2}$ Similarly more than half of participants reported by Abushouk recognized lack of research knowledge as a hurdle in their research work. ${ }^{9}$ The lack of research knowledge is inadequate understanding of the concepts of research, especially the statistical concepts and lack of skill in scientific writing. This problem can be solved by including research methodology courses and holding regular practical workshops to increase the knowledge of students in research methodology.

Analysis of perceptions of deficient potential of faculty towards research knowledge and skill by postgraduate residents of Balochistan identified item no. ${ }^{5}$ "Insufficient faculty research knowledge and skills" as a major obstacle $(68 \%)$ in scientific activities of postgraduate residents. In comparison $74 \%$ postgraduate residents of Imran Saeed from Children's Hospital, Lahore, were not satisfied with research knowledge of their faculty. However, other researchers observed this item as a research hurdle in much lower proportion of cases. Soe reported $26.6 \%$ respondents identified untrained faculty 3 and $37.1 \%$ participants of Amin et al study agreed low faculty knowledge working as a barrier towards their research work. ${ }^{8}$

An equal number of respondents from Quetta and Lahore identified Item "lack of interest in research work," causing deficiencies in their research activities due to over loaded curriculum. The reason behind lack of interest is probably that in the current curriculum of medical/dental institutions research is not mandatory. ${ }^{13,14}$

We did not find any statistically significant differences in opinions expressed by respondents from the two provinces on the remaining three variables viz uncooperative faculty, inaccessibility of electronic and medical data and lack of funding. The discrepancy of opinions probably reflects greater sensitization of faculty, better record keeping and more access to research funds in Punjab. However, the authors have not explored the casual relationship any further in their study.

\section{ACKNOWLEDGEMENTS}

The authors wish to extend their appreciation for voluntary participation of postgraduate residents from Balochistan \& Children's Hospital Lahore in study.

\section{LIMITATION OF STUDY}

In both studies of Punjab and Balochistan, self-administered questionnaire was utilized which may result in res- 


\section{Research Obstacles}

pondent bias. Study of Children's Hospital, Lahore carries the perceptions of research hurdles among postgraduate residents of only one medical institute and hence cannot be generalized to all postgraduate trainees.

Post-graduate residents of different areas face different obstacles during their scientific activities, contingent upon conditions, cultural and educational backgrounds. The most important factors of one area may be less prominent elements for the postgraduate residents of other region.

\section{CONCLUSION}

Medical and dental postgraduate trainees from diverse socio-economic, cultural and educational background have different perceptions about research hurdles. Four major issues identified were lack of mentoring, deficient laboratory and other facilities, lack of time and lack of motivation Data reported in this research has important implications for all stakeholders and should be used to inform decisions about reorganizing and restructuring research agenda of medical and dental institutions.

\section{Conflict of Interest: None.}

\section{Authors' Contribution}

NFK \& IS: Conceiv idean, manuscript writing, data anlaysi, MS: Data collection, study setting \& designing, AKB: Critical appraisal \& final approval.

\section{REFERENCES}

1. Sheikh ASF, Sheikh SA, Kaleem A, Waqas A. Factors contributing to lack of interest in research among medical students. Adv Med Educ Pract 2013; 4(1): 237-243.

2. Dadipoor S, Ramezankhani A, Teamur Aghamolaei AS-M. Barriers to research activities as perceived by medical university students: A cross-sectional study. Avicnna J Med 2019; 9(1): 8-14.

3. Soe HHK, Than NN, Lwin H, Htay MNNN, Phyu KL, Abas AL. Knowledge, attitudes, and barriers toward research: The perspectives of undergraduate medical and dental students. J Educ Heal Promot 2018; 7(1): 23-28.

4. Ahmed I. Medical Research in Pakistan. Isra Med J 2018; 10(6): 325-326.

5. Saeed I, Nhan FK, Bari A, Khan RA. Factors contributing to the lack of interest in research activities among postgraduate medical students. Pak J Med Sci 2018; 34(4): 913-917.

6. Saeed I, Khan NF, Butt AK. Impact of marital status on postgraduate medical students research activities. Pak J Med Health Sci. 2018; 12(4): 1574-1576.

7. Khan NF, Saeed M, Saeed U. Correlation between demographic perspective of pg trainees and research: a cross-sectional multidisciplinary study. J Pakistan Dent Assoc 2020; 29(1): 24-29.

8. Amin TT, Kaliyadan F, Al Qattan EA, Al Majed MH, Al Khanjaf HS, Mirza M. Knowledge, attitudes and barriers related to participation of medical students in research in three Arab Universities. Educ Med J 2012; 4(1): 43-56.

9. Abushouk AI, Hatata AN, Omran IM, Youniss MM, Elmansy KF, Meawad AG. Attitudes and perceived barriers among medical students towards clinical research: a cross-sectional study in an Egyptian medical school. J Biomed Educ 2016, [Internet] Avail- able at https://www.hindawi.com/journals/jbe/2016/5490575/ (Accessed on August 18, 2019)

10. Kharraz R, Hamadah R, Alfawaz D, Attasi J, Akef S, Alkattan W, et al. Perceived barriers towards participation in undergraduate research activities among medical students at Alfaisal University-College of Medicine: A Saudi Arabian perspective Perceived barriers towards participation in undergraduate research activities. Med Teach 2016; 38(Suppl-1): S12-18.

11. Kakar B, Tobwal U, Bareach K, Sultan RS. Social and Cultural Barrier to female Education in Balochistan; an Assessment study with focus on district Pishin. Balochistan Rev 2019; 2(1): 163-172.

12. Policy Framework for Gender Equality and Empowerment of Women. Women Develpoment Programme, Government of Balochistan 2012, [Internet] Available at: https://balochistan. gov.pk/departments/women-development-2/ (Assessed on June 2, 2019)

13. Shaikh AAG, Hashmi SK. BDS curriculum. Pakistan Medical and Dental Council \& Higher Education Commission. 2012, [Internet] Available at: http://www.pmdc.org.pk/LinkClick.aspx? fileticket $=06 \mathrm{HF}+1 \mathrm{ta} 1 \mathrm{uc}=\&$ tabid $=292 \& \mathrm{mid}=849$ (Assessed on July 7, 2019)

14. Shaikh AAG, Hashmi SK. Curriculum of MBBS - Pakistan Medical \& Dental Council. Pakistan Med Dent Assoc High Educ Commision Pakistan, Islamabad. 2012, [Internet] Available from: http://www.pmdc.org.pk/LinkClick.aspx?fileticket=EKfBIOSD TkE\%3D. (Assessed on January 20, 2020)

15. Egwuatu VE, Umeora O. A comparative study of marital status on the academic performance of the female medical undergraduate in a Nigerian university. Niger Postgr Med J 2007; 14(3): 175-179.

16. Thomas J, Raynor M, Al-marzooqi A. Marital status and gender as predictors of undergraduate academic performance : a United Arab Emirates context. Learn Teach High Educ 2012; 9(2010): 1-9.

17. Coombs RH. Marital status and personal well-being: a literature review. Fam Relat 2015; 40(1): 97-102.

18. Odegard O. Marriage and mental disease:- a study in social psychopathol. J Ment Sci 1946; 92(1): 35-59.

19. Abou-Elhamd K-EA, Al-Wadaani HA, Saleh AlMulhim AR. female medical undergraduate; does marriage affect the academic performance in a Saudi University? Prof Med J 2014; 21(3): 566-569.

20. Kunanitthaworn N, Wongpakaran T, Wongpakaran N, Paiboonsithiwong S, Songtrijuck N, Kuntawong P, et al. Factors associated with motivation in medical education: a path analysis. BMC Med Educ 2018; 18(1): 140.

21. Blašková M, Majchrzak-Lepczyk J, Hriníková D, Blaško R. Sustainable academic motivation. Sust 2019; 11(21): 1-24.

22. Patel S, Walsh CM, Udell JA. Exploring medically-related Canadian summer student research programs: a national cross-sectional survey study. BMC Med Educ 2019; 19(1): 1-9.

23. Wouters A, Croiset G, Galindo-garre F, Kusurkar RA. Motivation of medical students: selection by motivation or motivation by selection. BMC Med Educ 2016; 16(37): 1-9.

24. Hayat AA, Salehi A, Kojuri J. Medical student's academic performance: The role of academic emotions and motivation. J Adv Med Educ Prof 2018; 6(4): 168-175.

25. Morina A. The keys to learning for university students with disabilities: Motivation, emotion and faculty-student relationships. PLoS One 2019; 14(5): 1-15. 